INFLAMMATION AND INFLAMMATORY BOWEL DISEASE

\title{
Inducible CD40 expression mediates NFKB activation and cytokine secretion in human colonic fibroblasts
}

\author{
C M Gelbmann, S N Leeb, D Vogl, M Maendel, H Herfarth, J Schölmerich, W Falk, G Rogler
}

Gut 2003;52:1448-1456

See end of article for authors' affiliations

Correspondence to:

Dr G Rogler, Department

of Internal Medicine I

University of Regensburg,

93042 Regensburg,

Germany;

gerhard.rogler@

klinik.uni-regensburg.de

Accepted for publication 28 May 2003
Background: CD40 has been shown to be a functional activation antigen on a variety of cell types involved in immune responses. As intestinal fibroblasts and myofibroblasts may play a role during mucosal inflammation, we investigated the functional consequences of CD40 induction in primary cultures of human colonic fibroblasts.

Methods: Primary colonic lamina propria fibroblasts (PCLF) were isolated from endoscopic biopsies and surgical specimens. Cultures were used between passages 3 and 9. CD40 surface display was determined by FACS analysis and mRNA expression by reverse transcription-polymerase chain reaction. Secretion of cytokines was determined by ELISA. Nuclear factor $\kappa B(N F \kappa B)$ activation was shown by electrophoretic mobility shift assay (EMSA).

Results: After priming with interferon $\gamma($ IFN- $\gamma)(200 \mathrm{U} / \mathrm{ml})$ for 72 hours, five of eight tested PCLF cultures showed induction of CD40 surface display (up to 10-fold). Induction of CD40 mRNA expression was demonstrated by semiquantitative polymerase chain reaction. In the responder-PCLF cultures, IFN- $\gamma$ alone caused a 1.5-5-fold increase in interleukin (IL)-8 secretion. Addition of $1 \mathrm{ng} / \mathrm{ml} \mathrm{CD4OL}$ was sufficient to achieve a further increase in IL-8, IL-6, or monocyte chemotactic protein 1 (MCP-1) secretion (2.5-18-fold of controls). Incubation with CD40L alone without priming with IFN- $\gamma$ had no effect. The proteasome inhibitor N-acetyl-leucinyl-leucinyl-norleucinal (ALLN $100 \mu \mathrm{M}$ ) reduced IFN- $\gamma /$ CD4OL mediated cytokine induction, suggesting participation of $N F_{\kappa} B$, which was directly demonstrated by EMSA. CD4+ T cells induced MCP-1 secretion by PCLF, which was prevented by addition of an excess of CD40-lgG fusion protein. CD40 expression on PCLF could also be demonstrated in vivo by immunohistochemistry. Conclusion: The CD40-CD40L pathway augments mucosal inflammatory responses via mucosal PCLF. CD40-CD40L mediated T cell/PCLF interactions could play an important role during intestinal mucosal inflammation.
M esenchymal cells such as fibroblasts, myofibroblasts, or smooth muscle cells produce a number of mediators known to be important effectors during inflammation. Skin, synovial, and pulmonary mesenchymal cells can secrete growth factors such as granulocyte colony stimulating factor and granulocyte macrophage-colony stimulating factor, ${ }^{1}$ interleukins (IL) such as IL-1, IL-6, or IL-8, ${ }^{2-6}$ or chemokines such as RANTES or monocyte chemotactic protein 1 (MCP-1). ${ }^{7}$ These mediators have been shown to play an important role in the pathogenesis of inflammatory bowel disease (IBD) (for a review see Rogler and Andus ${ }^{8}$ ). Cytokine and chemokine secretion is upregulated by bacterial lipopolysaccharide ${ }^{5-11}$ or by contact with T cells, ${ }^{12}$ suggesting a role of mesenchymal cells during host defence. Hitherto only few studies have investigated the role of intestinal mesenchymal cells as active participants in mucosal inflammation and the pathogenesis of IBD.

CD40, a 45-50 kDa membrane glycoprotein of 277 amino acids, was originally described as a functionally important B cell surface molecule. ${ }^{13-15}$ The ligand for CD40, CD40L, is a 33-39D glycoprotein of 261 amino acids, which is a member of the tumour necrosis factor (TNF) superfamily. ${ }^{15-17}$ In recent years it has become clear that CD40 is not only expressed by B cells but by many other cell types such as antigen presenting cells, ${ }^{18-20}$ endothelial cells, epithelial cells from different organs, and fibroblasts. ${ }^{21-25}$ CD40L is produced as a type II transmembrane protein and may be present on the cell surface as a heteromultimeric complex, composed of membrane bound and soluble forms. ${ }^{26-28}$ Apart from its $33 \mathrm{kDa}$ form two shorter versions of the protein $(31 \mathrm{kDa}$ and $18 \mathrm{kDa}$ ) exist as soluble proteins. ${ }^{29} 30$ The receptor, CD40, activates several second messenger systems, including protein-tyrosine kinases, phosphatidylinositol 3-kinase, phospholipase $\mathrm{C} \gamma 2$, and serine-threonine stress activated protein kinases. ${ }^{31} 32$ These different pathways finally result in activation of transcription factors such as nuclear factor $\kappa \mathrm{B}(\mathrm{NF} \kappa \mathrm{B})$ or NF-AT. ${ }^{31} 32$

Several proteins were shown to interact with the intracellular domain of CD40. The first molecule identified was CD40 binding protein (CD40bp) now termed TRAF3 (TNF receptor associated factor 3). ${ }^{33-36}$ Besides TRAF3, CD40 associates with TRAF2 ${ }^{37}$ as well as TRAF5 ${ }^{38}$ and TRAF6. ${ }^{39} 40$

Ligation of CD40 by CD40L may be involved in several autoimmune diseases and, interestingly, CD40L antibodies abrogated experimental colitis in mice. ${ }^{41-43}$ Recent data also demonstrated a functional role of the CD40-CD40L system on mesenchymal cells (for example, human synovial and lung fibroblasts and airway smooth muscle cells). ${ }^{22} 2425274445$ Fibroblast activation by the CD40/CD40L system could be

\footnotetext{
Abbreviations: ALLN, N-acetyl-leucinyl-leucinyl-norleucinal; BSA, bovine serum albumin; $C D$, cluster of differentiation; $D A B$, diaminobenzidine; DMEM, Dulbecco's modified Eagle's medium; EMSA, electrophoretic mobility shift assay; FCS, fetal calf serum; HBSS, Hank's buffered salt solution; IBD, inflammatory bowel disease; IEC, intestinal epithelial cells; IFN, interferon; IL, interleukin; ICAM-1, intercellular adhesion molecule 1; LPMNC, lamina propria mononuclear cells; MCP-1, monocyte chemotactic protein $1 ; N F \kappa B$, nuclear factor $\kappa B$; PBS, phosphate buffered saline; PCLFs, primary human colonic lamina propria fibroblasts; TNF, tumour necrosis factor; TRAF, TNF receptor associated factor
} 
increased by pretreatment of cells with interferon $\gamma$ (IFN$\gamma){ }^{24}{ }^{46}$ Recently, we demonstrated that colonic fibroblasts secrete a row of inflammatory cytokines but the mechanisms involved in the regulation of cytokine secretion by these cells have still to be examined. ${ }^{9}$

CD40 has been suggested to play a role in IBD pathophysiology. Liu et al found increased expression of CD40L on freshly isolated lamina propria $\mathrm{T}$ cells from IBD patients compared with controls. They identified increased numbers of CD40+ and CD40L+ cells in IBD mucosa, being B cells, macrophages, and CD4+ T cells, respectively. ${ }^{47}$ In peripheral blood of Crohn's disease patients, increased numbers of CD40+ monocytes and CD40+ dendritic cells were found. ${ }^{48} 49$ The pathophysiological role of the CD40/CD40L system in IBD was further supported by the immunohistochemical demonstration of increased numbers of CD40+ cells in ulcerative colitis mucosa ${ }^{50}$ and by the finding of increased blood levels of CD40L, particularly in Crohn's disease. ${ }^{51}$

These data indicate that the CD40-CD40L system may be of relevance for secretion of inflammatory mediators by intestinal fibroblasts during the pathogenesis of IBD. We therefore addressed this question in vitro using cultures of isolated primary human colonic lamina propria fibroblasts (PCLFs) and by immunohistochemistry.

\section{MATERIAL AND METHODS Patients}

PCLF cultures were isolated from either endoscopic biopsies or surgical specimens. Cultures from eight patients without macroscopic or histological signs of inflammation (mean age 47.2 (17.2) years) were used. The study was approved by the University of Regensburg Ethics Committee.

\section{Isolation of intestinal fibroblasts}

In the case of surgical specimens, mucosa was stripped from submucosa, minced in $1 \mathrm{~mm}$ pieces, and placed in Dulbecco's modified Eagle's medium (DMEM) (PAA, Cölbe, Germany) with $20 \%$ fetal calf serum (FCS) (Gibco, Karlsruhe, Germany). Endoscopic biopsies were placed in sterile DMEM with 10\% FCS and PenStrep (Gibco, Karlsruhe, Germany). Epithelial cells were removed and lamina propria fibroblasts isolated and cultured as described previously. Cells were used between passages 3 and 9 .

\section{Immunohistochemistry}

\section{Characterisation of colonic PCLF}

The following antibodies were used for characterisation of PCLF: vimentin (Clone V9; Abcam, France), antifibroblast antibody ASO2 (Dianova, Hamburg, Germany), $\alpha$-smooth muscle cell actin (Clone 1A4; Dako, Hamburg, Germany), CD45 (Clone HI30; Pharmingen, San Diego, California, USA), EP4 (Clone Ber-EP4; Dako), cytokeratin 18 (Clone DC10; Coulter-Immunotech, Krefeld, Germany), CD68 (Clone KP1; Dako), CD3 (Clone UCHT1; Coulter-Immunotech), antihuman fibroblast surface protein (Clone 1B10; Sigma, Taufkirchen, Germany), isotype control IgGl (MOPC 21; Sigma), isotype control IgG2 (MOPC-141; Sigma), isotype control IgG3 (FLOPC-21; Sigma).

Cells were seeded onto LabTek Chamber slides (Nunc, Wiesbaden, Germany). After fixation with 3.7\% formaldehyde, endogenous peroxidase was inactivated by incubation with $0.3 \% \mathrm{H}_{2} \mathrm{O}_{2}$ for 30 minutes. Blocking was done with $1 \%$ bovine serum albumin (BSA) for 30 minutes. Cells were incubated with the primary antibody for one hour and with a biotin-SP conjugated rabbit antimouse IgG antibody (Dianova, Baltimore, Pennsylvania, USA) for 30 minutes followed by the avidin biotin complex (Zymed, San Francisco, California, USA) for one hour (all at room temperature). Binding of antibodies was visualised with
$0.03 \%$ 3-3' diaminobenzidine (DAB) (Sigma, St Louis, Missouri, USA) and $0.003 \%$ hydrogen peroxide until a brown reaction product could be seen.

Immunohistochemical double staining

For double labelling of freeze sections, additional anti-CD40 (clone MAB89; Coulter) and anti-intercellular adhesion molecule 1 (ICAM-1; Dianova) were used. Tissue sections were fixed in 3.7\% buffered formaldehyde followed by acetone (50\%, 100\%, 50\%; two minutes each) and rehydrated in $0.1 \mathrm{M}$ phosphate buffered saline (PBS) followed by $1 \%$ BSA for blocking. Incubation with anti-CD40 was performed overnight at $4^{\circ} \mathrm{C}$. Incubation with the biotinylated secondary antibody (Dianova) was performed at room temperature for one hour. Staining with DAB was done as described for PCLF cultures.

For double staining, the remaining peroxidase was suppressed by incubation in $0.3 \%$ hydrogen peroxide for 30 minutes. Sections were then incubated with the second incubation series consisting of primary and secondary antibodies and avidin biotin complex, as described above. For colour reaction, the specimen was incubated according to the VectorVIP (purple) (Vector Laboratories, Burlingame, California, USA) protocol producing an intense purple coloured precipitate.

\section{Stimulation experiments with PCLF}

Cells were seeded into sixwell plates (Falcon, Heidelberg, Germany) at a density of $2-5 \times 10^{5}$ per well. Cells were grown to confluence before stimulation experiments to ensure comparable conditions, with the majority of cells in the $G_{0}$ phase of the cell cycle.

Cultured PCLF were stimulated for the indicated periods. $N$-acetyl-leucinyl-leucinyl-norleucinal (ALLN) $100 \mu \mathrm{M}$ was added to the medium in parallel for inhibition of $\mathrm{NF \kappa B}$ activation. After the incubation period, medium was removed for determination of secreted proteins and cells were harvested with $1 \%$ sodium dodecyl sulphate in PBS for protein assay.

\section{Determination of cytokine protein}

Cytokines were measured by ELISA (Biotrak-Amersham, Braunschweig, Germany or R\&D systems, Wiesbaden, Germany) according to the manufacturer's protocol.

\section{FACS analysis of CD40 expression on PCLF}

Flow cytometry was performed using an EPICS flow cytometer (Coulter, Miami, USA) equipped with an argon ion laser with an excitation power of $15 \mathrm{~mW}$ at $488 \mathrm{~nm}$. Cells were incubated with FITC labelled anti-CD40 antibody or isotype control for two hours at $4^{\circ} \mathrm{C}$ in the dark. Acquisition was performed on unfixed cells. For data analysis, WIN-MDI software was used.

\section{Reverse transcription-polymerase chain reaction (RT- PCR) for CD40, CD40L, and TRAF3 mRNA}

Total mRNA from cell cultures was prepared using RNeasy columns (Qiagen, Hilden, Germany). Reverse transcription was performed with the reverse transcription system of Promega (Mannheim, Germany). A 900 bp fragment of the CD40 cDNA was amplified using the 5' primer aatctagatgccgectggtctcacctcg and the $3^{\prime}$ primer aaaagcttgccaactgcctgtttgccacg. A 630 bp fragment of the CD40L cDNA was amplified using the $5^{\prime}$ primer cggccactggactgcccatcagc and the $3^{\prime}$ primer gccogcaaggtttggcggaactg. A $300 \mathrm{bp}$ fragment of the TRAF3 CDNA (CD40bp) was amplified using the $5^{\prime}$ primer cctgcgagaccacgtggagaaggcg and the $3^{\prime}$ primer gcaggttgacgtgctgcacggcgg. The PCR conditions were $1 \times \mathrm{PCR}$ buffer, $200 \mu \mathrm{mol} / \mathrm{l}$ dNTPs, $0.5 \mu \mathrm{mol} / \mathrm{l}$ primer, $0.5 \mathrm{U}$ Taq 
polymerase, and $0.125 \mu \mathrm{g}$ cDNA for each PCR. PCR conditions were: $94^{\circ} \mathrm{C}$, five minutes; $94^{\circ} \mathrm{C}, 30$ seconds; $68^{\circ} \mathrm{C}$, one minute, $72^{\circ} \mathrm{C}, 45$ seconds.

\section{Isolation of LPMNC, CD33+ macrophages, and CD4+ T cells}

Isolation of lamina propria mononuclear cells (LPMNC) and CD33 positive intestinal macrophages was performed essentially as described previously.5. ${ }^{52}$ Isolated LPMNCs were sorted by immunomagnetic beads coated with monoclonal antibodies against CD33 (intestinal macrophages) or CD4 (T helper cells) (MACS Beads, Miltenyi Biotec, Bergisch Gladbach, Germany) with a separation column and a magnetic separator from the same company.

\section{Electrophoretic mobility shift assay (EMSA)}

Nuclear extracts from PCLF were prepared as described previously. ${ }^{53}$ The prototypic double stranded immunoglobulin kappa chain oligonucleotide (5'-CAGAGGGACTTT CCGAGA$\left.3^{\prime}\right)$ was used as a probe and labelled by annealing of complementary primers followed by primer extension with the Klenow fragment of DNA polymerase I (Boehringer Mannheim, Mannheim, Germany) in the presence of $\left[\alpha^{32} \mathrm{P}\right] \mathrm{dCTP}(>3.0 \mathrm{Ci} / \mathrm{mmol}$; Amersham, Arlington Heights,
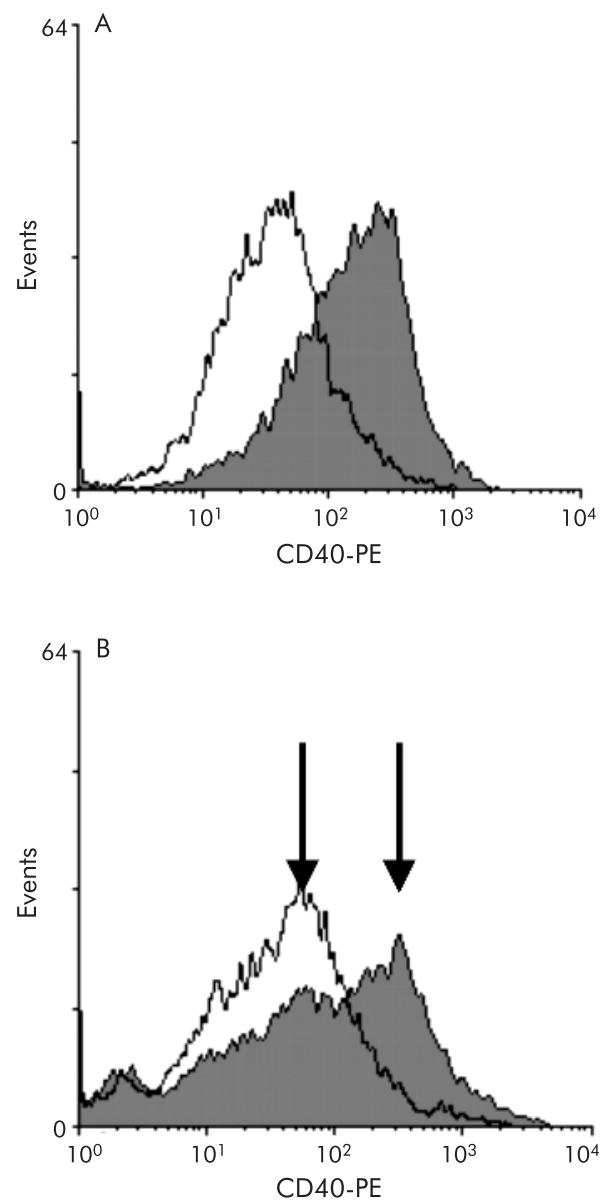

Figure 1 FACS analysis of interferon $\gamma$ (IFN- $\gamma$ ) induced CD40 expression on colonic primary human colonic lamina propria fibroblasts (PCLFs). Histogram of FITC-anti-CD40 fluorescence on colonic PCLFs with and without IFN- $\gamma$ preincubation $(200 \mathrm{U} / \mathrm{ml}, 72$ hours). IFN- $\gamma$ induced an up to 10-fold increase in FITC fluorescence (filled graph) compared with uninduced cells (open graph) $(A)$ in five of eight cultures. In two of the cultures not all cells showed induction of CD40 expression, indicated by two peaks in the histogram ((B); IFN- $\gamma$ primed cells: filled graph).
Illinois, USA) and deoxynucleoside triphosphates I (Boehringer Mannheim, Mannheim, Germany) as described previously. ${ }^{53}$ Nuclear extracts ( $5 \mu \mathrm{g}$ protein) were incubated with radiolabelled DNA probes $\left(\approx 10 \mathrm{ng}, 10^{5} \mathrm{cpm}\right)$ for 30 minutes at room temperature..$^{53}$ Samples were run in $0.25 \times$ TBE buffer non-denaturing $6 \%$ polyacrylamide gels at $125 \mathrm{~V}$ for three hours. Equal amounts of protein were loaded onto the gels. Gels were analysed by autoradiography.

\section{Statistics}

Unless stated otherwise, all data are given as mean (SD). Statistical analysis was performed using the Student's $t$ test for unpaired samples or the Mann-Whitney rank sum test as indicated.

\section{RESULTS}

\section{IFN- $\gamma$ induced CD40 expression on PCLF}

Eight different PCLF cultures isolated from non-inflamed mucosa of control patients were used for the experiments. PCLF cultures were characterised with the antibody panel given in the methods section to exclude contamination with

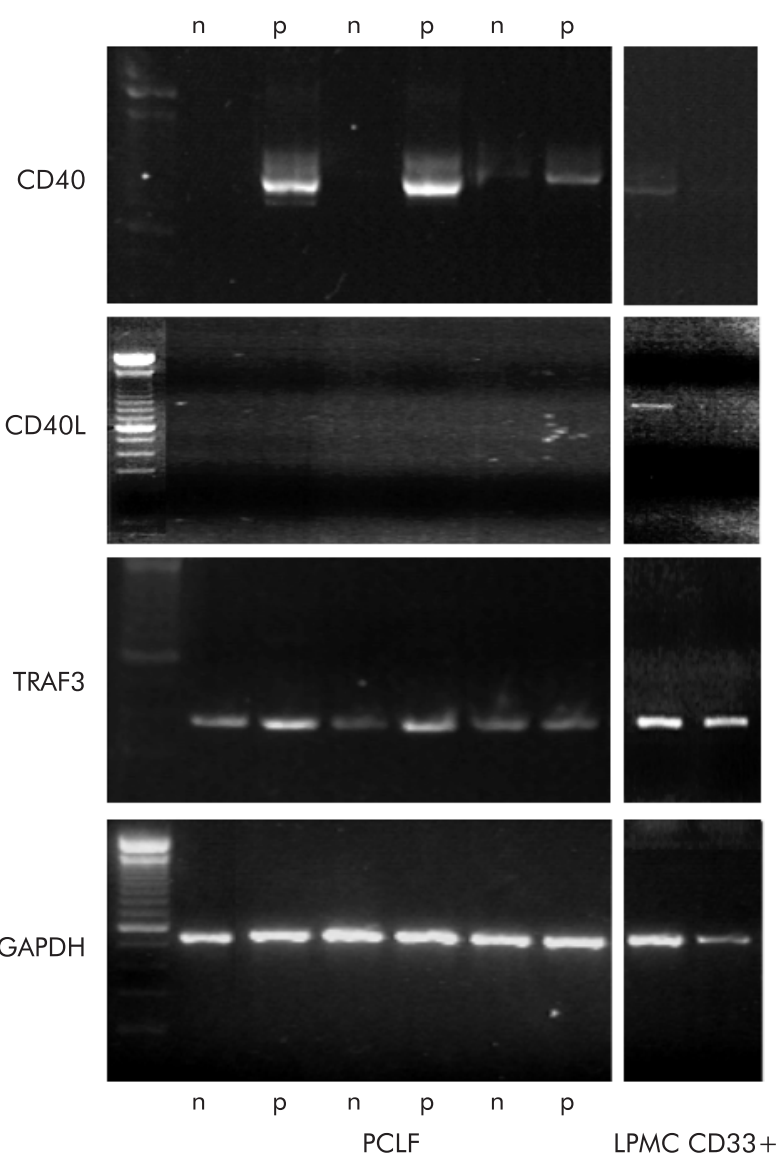

Figure 2 Reverse transcription-polymerase chain reaction (RT-PCR) for CD40, CD40 ligand (CD40L), and tumour necrosis factor receptor associated factor (TRAF3) expression in primary human colonic lamina propria fibroblasts (PCLFs) with and without priming with interferon $\gamma$ (IFN- $\gamma$ ). RT-PCR for CD40 (900 bp fragment), for CD40L (630 bp fragment), TRAF3 (300 bp fragment), and glyceraldehyde-3-phosphate dehydrogenase (GAPDH 450 bp fragment) was performed and analysed on $1 \%$ agarose gels ( $n=$ non-stimulated, $p=I F N-\gamma$ primed). Three independent experiments are shown. IFN- $\gamma$ induced CD40 whereas CD4OL could not be amplified and the TRAF3 signal was not consistently influenced. The lymphocyte fraction (CD33 negative lamina propria mononuclear cells (LPMC)) and freshly isolated intestinal macrophages (CD33+) were used for comparison. The results are representative of three or more experiments. 

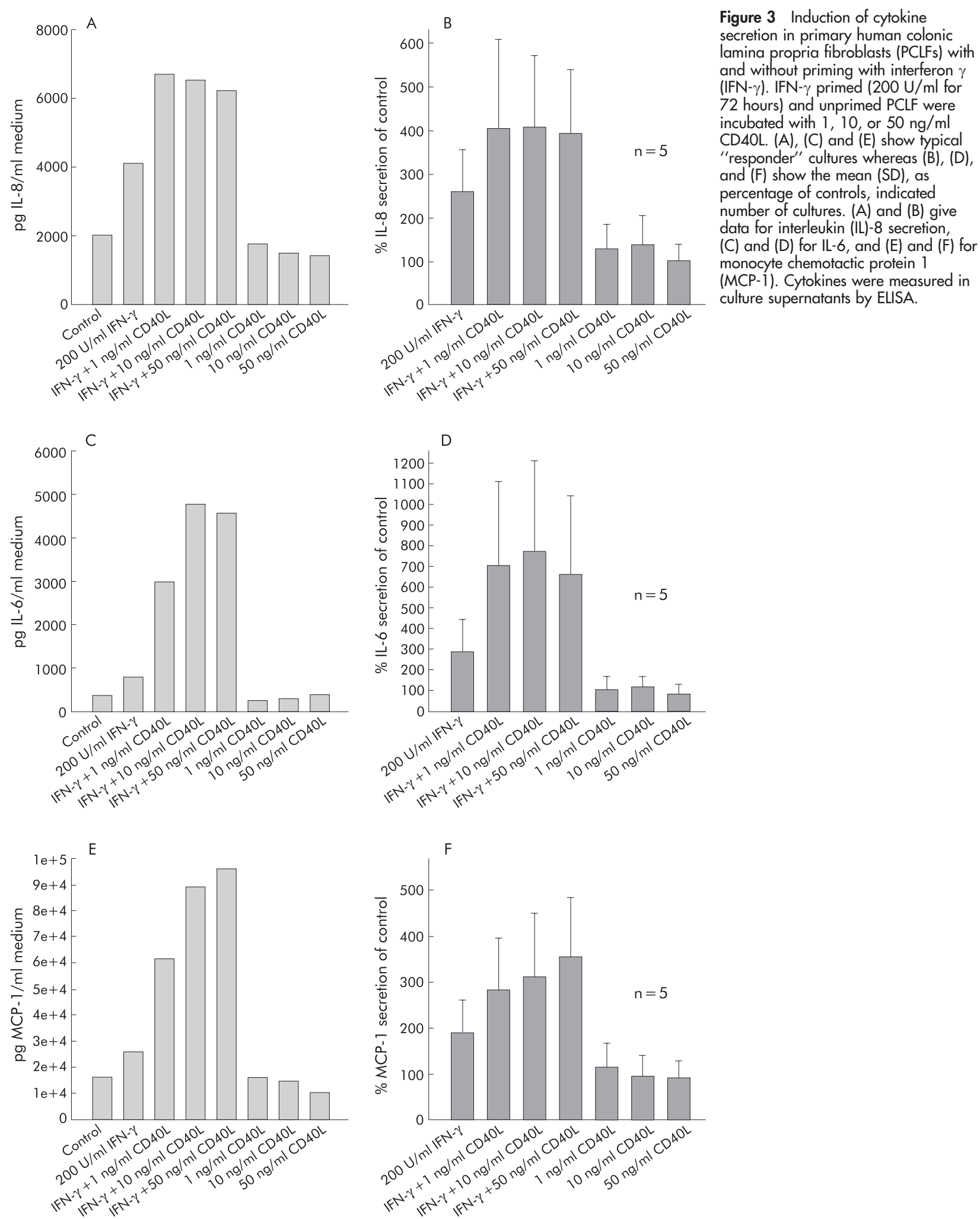

other cell types. All cultures were positive and homogeneously stained with antifibroblast antibody ASO2 as well as anti-vimentin. $\alpha$-Actin was positive in up to $40 \%$ of cells (range 6-40\%), indicating that PCLF cultures were not homogeneous. Homogeneity was not increased by passaging. After the third passage, CD45, CD3, CD68, or EP4 were positive in less than $1 \%$ of cultured cells, indicating the absence of lymphocytes, macrophages, or epithelial cells.
For induction of CD40 expression, PCLF cultures were primed with $200 \mathrm{U} / \mathrm{ml}$ IFN- $\gamma$ for 72 hours. Higher concentrations or longer incubation periods did not further increase CD40 surface expression. Lower concentration of IFN- $\gamma$ or shorter incubation periods caused lower numbers of CD40 positive cells in FACS analysis (data not shown).

In FACS analysis, five of eight primary PCLF cultures showed induction of CD40 expression after priming with 
IFN- $\gamma$ (fig 1A). Mean fluorescence was increased up to 10fold compared with control conditions. In two cultures only part of the PCLF population showed induction of CD40: two separate populations were observed with obvious difference in CD40 surface expression (fig 1B). The five cultures which showed CD40 expression after IFN- $\gamma$ stimulation were termed "responder PCLF cultures".

RT-PCR confirmed induction of CD40 mRNA by IFN- $\gamma$ in the responder PCLF cultures (fig 2A). Whereas no CD40 mRNA was detectable in unprimed PCLFs, incubation with $200 \mathrm{U} / \mathrm{ml} \mathrm{IFN}-\gamma$ led to the appearance of the expected amplicon. For confirmation, the PCR product was cloned and sequenced. For comparison, CD40 mRNA expression was also determined in lymphocytes and freshly isolated macrophages. A positive signal was observed in the lymphocyte fraction (CD33 negative LPMNC) whereas freshly isolated intestinal macrophages (CD33+) from normal mucosa were negative for CD40 mRNA ( fig 2).

CD40L mRNA was absent in PCLF and could not be induced with IFN- $\gamma$ (fig 2). However, CD40L mRNA was clearly expressed in the lamina propria lymphocyte population (CD33 negative LPMNC). Isolated colonic macrophages did not show CD40L mRNA, indicating that mainly lymphocytes express CD40L mRNA in the normal human intestinal mucosa (fig 2). TRAF3 (CD40bp) was constitutively expressed in all cells investigated (fig 2). These data indicate that CD40 mRNA expression is upregulated by IFN- $\gamma$ in PCLF and that CD40L mRNA is absent.

\section{Induction of cytokine secretion by CD40 ligation}

To investigate whether induction of CD40 protein expression on PCLF is followed by cell reactivity to soluble CD40L, we incubated for 72 hours IFN- $\gamma$ primed and unprimed PCLF cultures with 1,10 , or $50 \mathrm{ng} / \mathrm{ml}$ CD $40 \mathrm{~L}$. In the responder PCLF cultures, IFN- $\gamma$ alone caused a 1.5-5-fold increase in IL-8 secretion (fig 3A). Addition of $1 \mathrm{ng} / \mathrm{ml}$ CD40L was sufficient to achieve a further increase in cytokine secretion (2.5-18 fold of control) (fig 3B). Incubation with CD40L alone without prior IFN- $\gamma$ priming had no effect. Very similar results were found for IL-6 (fig 3C, D) and MCP-1 (fig 3E, F). The CD40L effect on cytokine secretion of PCLF after priming with IFN- $\gamma$ was strongest with respect to IL- 6 compared with IL-8 and MCP-1. Taken together, these results indicate that CD40L stimulation of responder PCLF enhanced cytokine secretion.

\section{Activation of NF $\kappa B$ by CD40 ligation}

As NFKB is involved in CD40 signalling in other cell types and is a potent regulator of IL-8, IL-6, or MCP-1 secretion, we investigated the possible role of NFKB for CD40 signalling in PCLF. The proteasome inhibitor ALLN $(100 \mu \mathrm{M})$ was tested for toxicity by trypan blue exclusion and propidium iodide cell cycle analysis. No evidence of toxic effects during the incubation period was found (data not shown). As shown in fig 4, ALLN alone reduced spontaneous MCP-1 secretion by PCLF, indicating basic activation of NFKB. Priming with IFN- $\gamma$ increased MCP-1 secretion. Addition of CD40L to unprimed cells had no effect on cytokine secretion whereas it doubled MCP-1 secretion in IFN- $\gamma$ primed cells. Addition of ALLN abolished the stimulating effect of CD40L on cytokine secretion of primed cells. This indicated that the proteasome inhibitor ALLN was able to antagonise the effect of CD40L on primed human PCLFs (fig 4).

To show that this effect was mediated by inhibition of NFKB activation, EMSA were performed (fig 5). Basal activation of $\mathrm{NF \kappa B}$ was found in non-stimulated cells (fig $5 \mathrm{~A}$, lane 1). Addition of $1 \mathrm{ng} / \mathrm{ml} \mathrm{CD} 40 \mathrm{~L}$ or $50 \mathrm{ng} / \mathrm{ml}$ CD40L strongly increased NFKB activation if cells had been preincubated with IFN- $\gamma$ (fig 5A, lanes 2 and 3). In contrast,

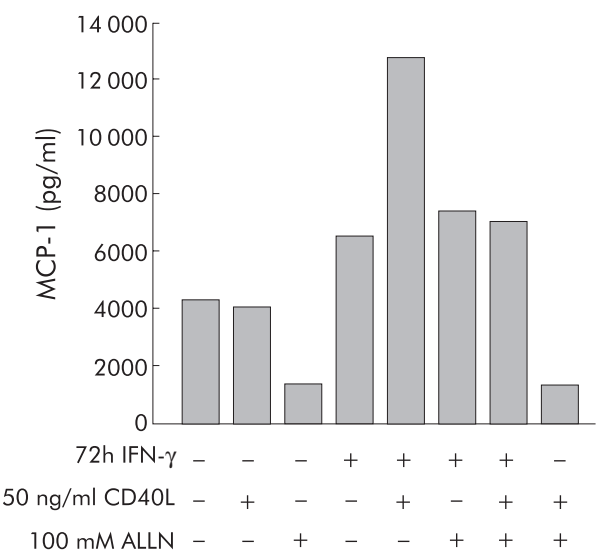

Figure 4 Effect of the protease inhibitor $\mathrm{N}$-acetyl-leucinyl-leucinylnorleucinal (ALLN) on monocyte chemotactic protein 1 (MCP-1) induction by CD40L. Interferon $\gamma($ IFN- $\gamma$ ) primed $(200 \mathrm{U} / \mathrm{ml}$ for 72 hours) primary human colonic lamina propria fibroblasts were incubated with CD4OL $(50 \mathrm{ng} / \mathrm{ml}$ ) and/or the proteasome inhibitor ALLN $(100 \mu \mathrm{M})$. MCP-1 secretion in medium supernatants was determined by ELISA. Data are representative of two independent experiments.

incubation of unprimed PCLF with 1 or $50 \mathrm{ng} / \mathrm{ml} \mathrm{CD40L} \mathrm{did}$ not activate NFKB (fig 5A, lanes 4 and 5). Addition of ALLN did not change the NFKB signal of untreated cells significantly (fig 5B, lanes 1 and 2). Priming with IFN- $\gamma$ was not followed by significant NFKB activation if ALLN was present (fig 5B, lane 3). Moreover, ALLN also prevented CD40L induced NFKB activation seen without addition of ALLN (fig 5B, lane 4).

\section{Effect of CD4+ T cells on PCLF cytokine secretion}

To test the functional relevance of upregulation of CD40 on PCLF by IFN- $\gamma$, we incubated responder PCLF cell cultures with freshly isolated peripheral blood CD4+ cells of different donors and measured MCP-1 secretion. The presence of CD40L on these cells was monitored by flow cytometry (data not shown). As indicated in fig 6, CD4+ cells did not produce MCP-1. PCLF showed basal secretion of MCP-1 which was further stimulated by priming with IFN- $\gamma$ (fig 6). Incubation of primed PCLF with CD4+ T cells was followed by clear stimulation of MCP-1 secretion to about $500 \%$ of the
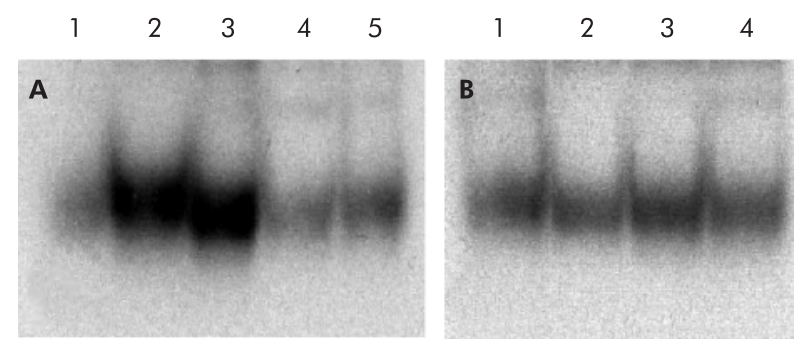

Figure 5 Effect of CD4OL on nuclear factor $\kappa B(N F \kappa B)$ activation in interferon $\gamma$ (IFN- $\gamma$ ) primed primary human colonic lamina propria fibroblasts (PCLFs). Electrophoretic mobility shift assay (EMSA) of cultured PCLF stimulated as indicated. (A) Baseline NFKB translocation in controls is seen (lane 1). After priming with IFN- $\gamma$ incubation with $1 \mathrm{ng} / \mathrm{ml}$ (lane 2) or $50 \mathrm{ng} / \mathrm{ml}$ (lane 3), CD4OL was followed by NFKB activation. Without priming, $1 \mathrm{ng} / \mathrm{ml}$ (lane 4) or $50 \mathrm{ng} / \mathrm{ml} \mathrm{CD40L} \mathrm{(lane}$ 5) did not cause significant NFKB activation. These data are representative of two independent experiments. (B) Baseline activation of $N F K B$ is seen in lane 1. Addition of $\mathrm{N}$-acetyl-leucinyl-leucinyl-norleucinal (ALLN) did not change the NFKB signal of unprimed cells significantly (lane 2). Priming with IFN- $\gamma$ was not followed by significant NFKB activation in the presence of $100 \mu \mathrm{M}$ ALLN (lane 3). ALLN $100 \mu \mathrm{M}$ also prevented CD40L induced NFKB activation (lane 4). 


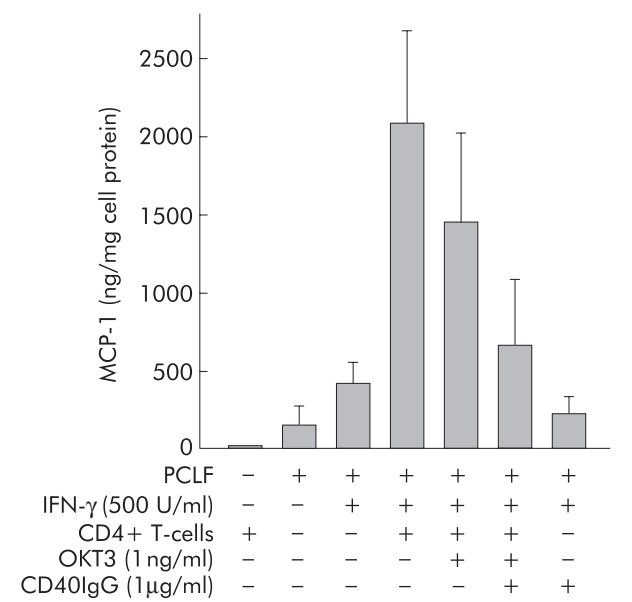

Figure 6 Effect of CD4+ cells and CD40lg G fusion protein on monocyte chemotactic protein 1 (MCP-1) secretion by primary human colonic lamina propria fibroblasts (PCLFs). Four "responder" PCLF cultures were incubated with freshly isolated peripheral blood CD4+ cells from two different donors each. MCP-1 secretion was measured by ELISA. PCLF showed basal secretion of MCP-1 which was further stimulated by priming with interferon $\gamma$ (IFN- $\gamma$ ). Incubation of primed PCLF with CD4+ T cells was followed by induction of MCP-1 secretion. Addition of neutralising antibody against CD3 (OKT3) reduced MCP-1 secretion, but not significantly. Addition of CD40lgG fusion protein $(1 \mu \mathrm{g} / \mathrm{ml})$ reduced MCP- 1 secretion significantly compared with IFN- $\gamma+C D 4$ cells and IFN- $\gamma+\mathrm{CD} 4$ cells+OKT3. secretion induced by IFN- $\gamma$ alone. The neutralising anti-CD3 antibody OKT3 (l ng/ml) had no significant effect on MCP-1 secretion of PCLF in coculture with CD4+ T cells. However, addition of CD40IgG fusion protein $(1 \mu \mathrm{g} / \mathrm{ml})$, which is thought to bind to CD40L present on CD4+ cells and inhibit the interaction of CD40L with CD40, reduced MCP-1 secretion almost to levels found with IFN- $\gamma$ priming alone. This reduction was highly significant compared with IFN- $\gamma+C D 4$ cells $(p=0.0004$; rank sum test; power of test with alpha $=0.0500: 0.9947)$. It was also significant compared with IFN- $\gamma+$ CD4 cells+OKT3 ( $p=0.02$; rank sum test). However, in this case the power of the test with alpha $=0.0500$ was only 0.6184 . These results indicate that $\mathrm{T}$ cells can stimulate PCLF to secrete chemokines or cytokines via CD40/CD40L interaction.

\section{Demonstration of CD40 induction on PCLF in vivo}

To investigate whether the in vitro data are relevant in vivo in IBD, we performed an immunohistochemical double staining for CD40, PCLF markers, EP4 as an epithelial cell marker, CD3 as a T cell marker, and ICAM-1 on five specimens in each group. In normal mucosa of biopsies of healthy donors, hardly any CD40 positive cells could be detected (brown reaction product, fig 7A). No colocalisation was found with the epithelial cell marker EP4 (fig 7B) or with the fibroblast markers ASO2 (fig 7C), vimentin (fig 7D), or $1 \mathrm{~B} 10$ (fig 7E). Isotype controls were negative (fig 7F).
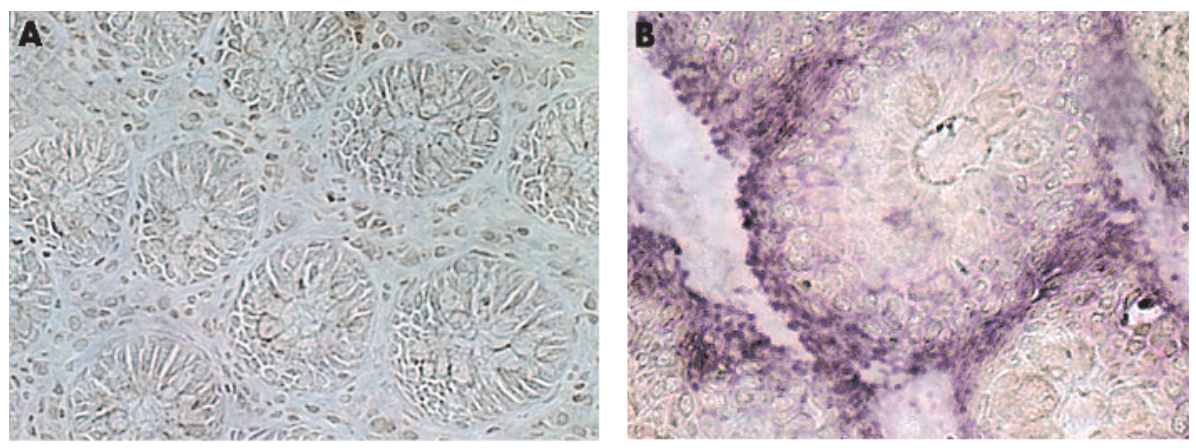

Figure 7 Immunohistochemical colocalisation of CD40 and fibroblast markers in normal mucosa. CD40 was visualised in all specimen by diaminobenzidine (brown reaction product). The indicated markers were stained in a second step with Vector violet (violet reaction product). (A) Almost absence of $C D 40$ positive cells. No colocalisation with the epithelial cell marker EP4 (B) or with the fibroblast markers ASO2 (C), vimentin (D), or $1 \mathrm{~B} 10$ (E). Isotype controls were negative (F).
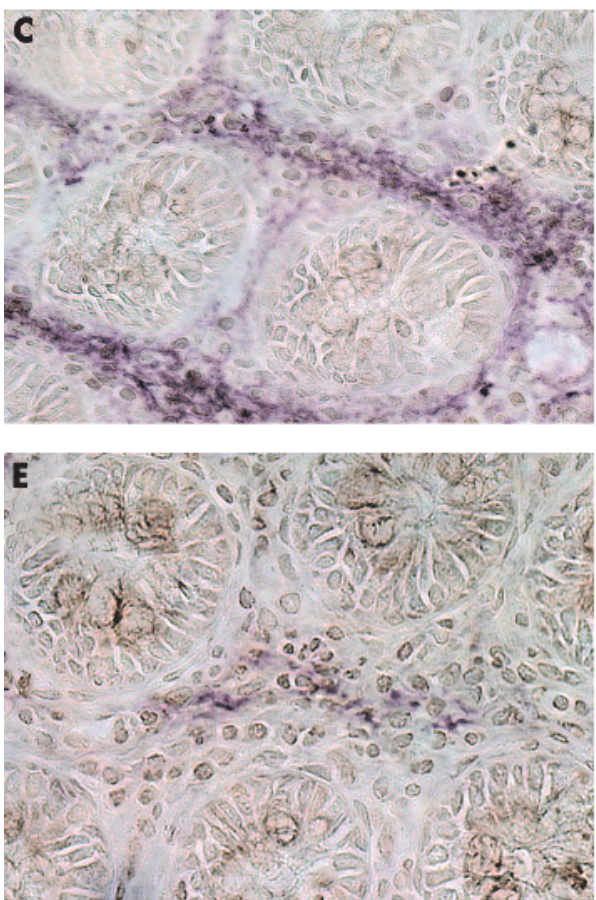

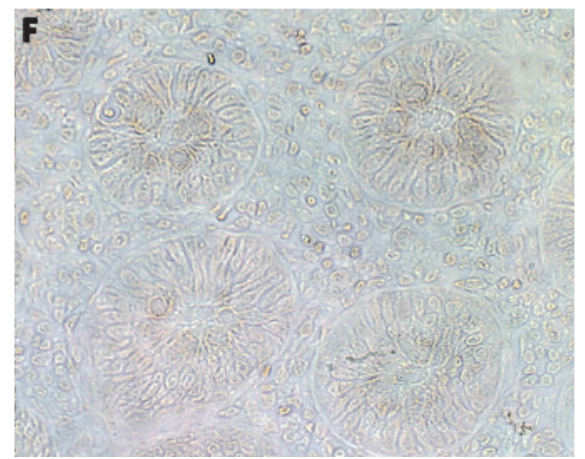



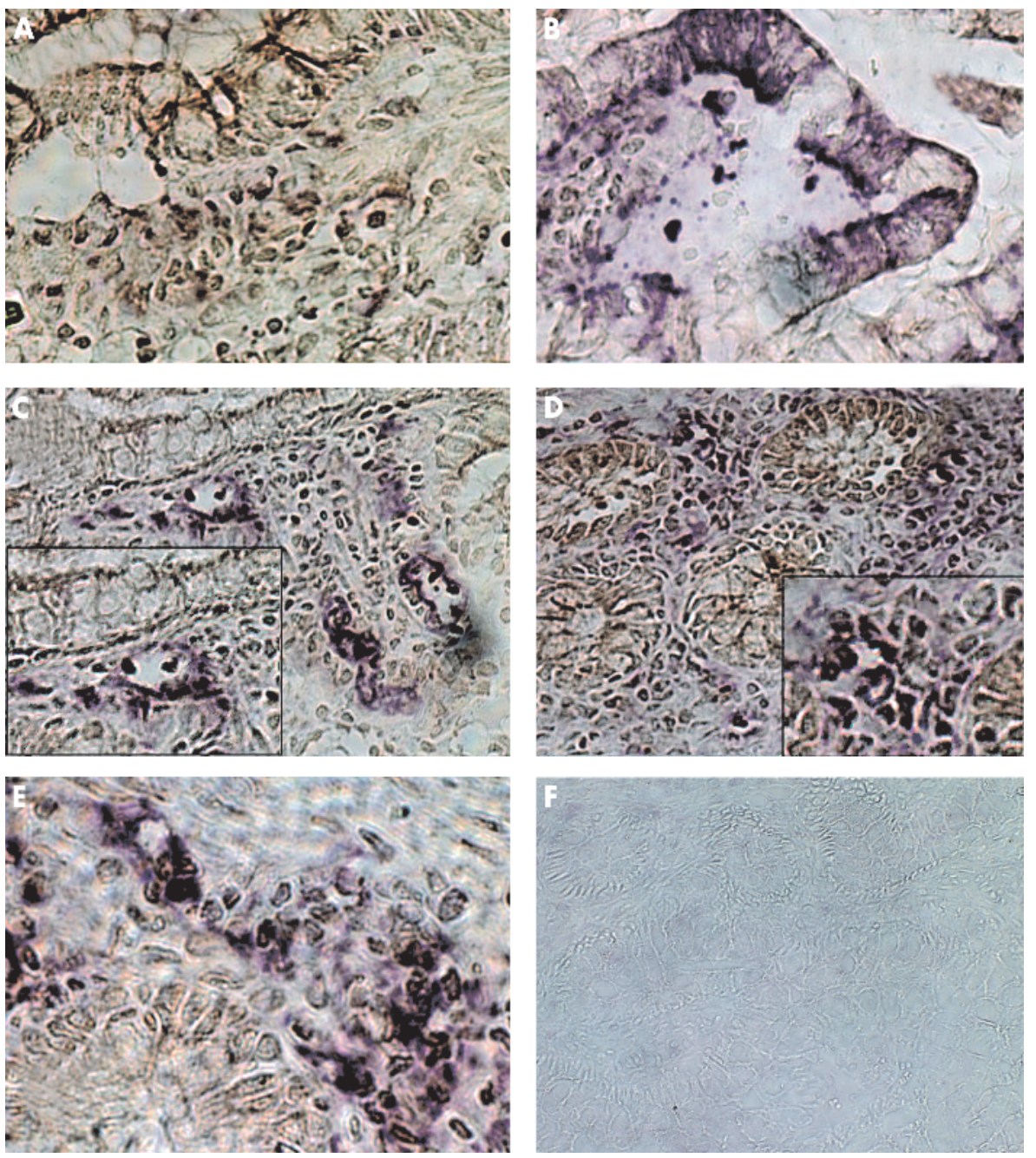

Figure 8 Immunohistochemical colocalisation of CD40 and fibroblast markers in Crohn's disease mucosa (inflamed area). A strong increase in the number of CD40 positive cells (brown reaction product) was observed (A). Lack of colocalisation with EP4 (epithelial cells) (B). Colocalisation with intercellular adhesion molecule 1 (ICAM-1), indicating expression on endothelial cells (C, see also insert with a small vessel). CD40 was colocalised with vimentin (D) and $\mathrm{ASO} 2(\mathrm{E})$, demonstrating the presence of CD40 on mesenchymal cells. (F) Isotype control.

\section{(1)}

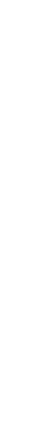

\section{列 \\ .}



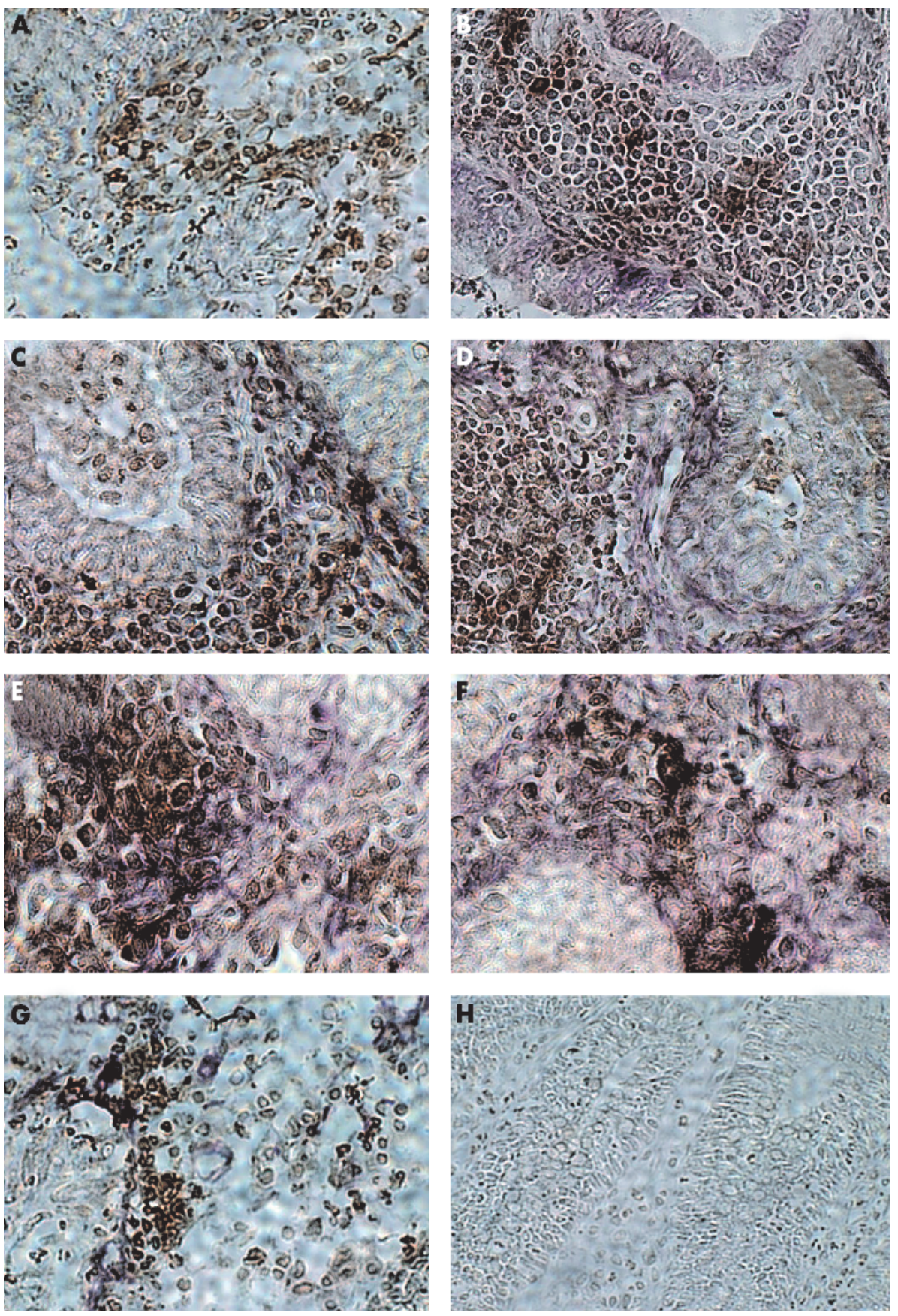

Figure 9 Immunohistochemical colocalisation of CD40 and fibroblast markers in active ulcerative colitis. (A) Increased number of CD40 positive cells in the lamina propria compared with control mucosa. No colocalisation with epithelial cells (EP4, (B)). Some of the CD40+ could be identified as T cells (C). Colocalisation with anti- $\alpha$ smooth muscle cells actin (D), ASO2 fibroblast marker $(\mathrm{E})$, vimentin $(\mathrm{F})$, and $1 \mathrm{~B} 10(\mathrm{G})$, indicating $C D 40$ induction on primary human colonic lamina propria fibroblasts during active ulcerative colitis. Lack of specific staining with isotype controls $(H)$.
It is important to note that CD40 expression on PCLF has to be induced by IFN- $\gamma$. As IFN- $\gamma$ is a major T cell product during a Th- 1 inflammatory response, it is obvious that an inflammatory reaction has to occur before PCLF can be activated. However, activated Th-1 cells in the vicinity of PCLF may induce CD40 expression on PCLFs and consecutively stimulate PCLF to secrete cytokines further activating T cells or macrophages inducing cell invasion into the inflamed tissue and a self perpetuating type of chronic inflammation.

It is not clear why not all cultures of PCLF could be primed by IFN- $\gamma$ to express CD40. Immunocytochemical characterisation of cultures revealed no obvious differences. Incubation with IFN $-\gamma$ alone, without ligation of CD40, induced cytokine secretion and NFKB activation after 72 hours. As there is no known direct activation of NFKB by IFN- $\gamma$, it is likely that apart from CD40, IFN- $\gamma$ induces another cytokine or mediator which is responsible for NFKB activation.
Among the molecules induced by CD40 ligation on PCLF are IL-8, which can attract neutrophils, MCP-1, which attracts monocytes/macrophages, and ICAM-1. It has been shown previously that activation of intestinal fibroblasts induces ICAM-1 surface expression and mRNA as well as adhesiveness for $\mathrm{T}$ cells. ${ }^{54}$ ICAM-1 may be essential for intestinal fibroblast binding of $\mathrm{T}$ cells. Musso et al concluded that intestinal fibroblasts may have a crucial regulatory role in mucosal immunity and that they may be potential targets for therapeutic intervention in intestinal inflammation. ${ }^{54}$ Our data proved evidence that interaction of CD40 with CD40L displaying T cells may induce ICAM-1 expression which then increases $\mathrm{T}$ cell adhesiveness and further improves the ability of fibroblasts to interact with $\mathrm{T}$ cells. Other chemokines relevant for the pathophysiology of IBD may be induced by CD40 ligation, as suggested by studies on fibroblasts from other origins..$^{2122225274445}$ Expression of matrix metallo- 
proteinases which are involved in tissue remodelling was also shown to be induced by CD40 ligation in vascular smooth muscle cells and in endothelial cells.

Induction and activation of CD40 on PCLF may therefore play a role during mucosal inflammation. As PCLF have an important role during formation of fistulae and especially strictures, further studies have to show whether the pathway described here is of pathophysiological relevance under those conditions. Particularly in patients with stricturing disease, inhibition of costimulated PCLF could yield therapeutic benefits.

\section{Authors' affiliations}

C M Gelbmann, S N Leeb, D Vogl, M Maendel, H Herfarth,

J Schölmerich, W Falk, G Rogler, Department of Internal Medicine I, University of Regensburg, Germany

\section{REFERENCES}

1 Hamilton JA, Piccoli DS, Cebon J, et al. Cytokine regulation of colonystimulating factor (CSF) production in cultured human synovial fibroblasts. II.Similarities and differences in the control of interleukin-1 induction of granulocyte-macrophage CSF and granulocyte-CSF production. Blood 1992;79:1413-19.

2 Maas-Szabowski N, Fusenig NE. Interleukin-1-induced growth factor expression in postmitotic and resting fibroblasts. J Invest Dermatol 1996;107:849-55.

3 Dongari-Bagtzoglou Al, Ebersole JL. Production of inflammatory mediators and cytokines by human gingival fibroblasts following bacterial challenge. $J$ Periodontal Res 1996;31:90-8.

4 Zhang S, Howarth PH, Roche WR. Cytokine production by cell cultures from bronchial subepithelial myofibroblasts. J Pathol 1996;180:95-101.

5 Burnstine MA, Elner SG, Strieter RM, et al. Orbital fibroblast interleukin-6 gene expression and immunomodulation. Ophthal Plast Reconstr Surg 1999; 15:306-11.

6 Sakurada S, Kato T, Okamoto T. Induction of cytokines and ICAM-1 by proinflammatory cytokines in primary rheumatoid synovial fibroblasts and inhibition by N-acetyl-L- cysteine and aspirin. Int Immunol 1996;8:1483-93.

7 Meyer JE, Berner I, Teran LM, et al. RANTES production by cytokine-stimulated nasal fibroblasts: its inhibition by glucocorticoids. Int Arch Allergy Immunol 1998; 117:60-7.

8 Rogler G, Andus T. Cytokines in inflammatory bowel disease. World J Surg 1998;22:382-9.

9 Rogler G, Gelbmann CM, Vogl D, et al. Differential activation of cytokine secretion in primary human colonic fibroblast/myofibroblast cultures. Scand J Gastroenterol 2001;36:389-98.

10 Elner VM, Burnstine MA, Kunkel SL, et al. Interleukin-8 and monocyte chemotactic protein-1 gene expression and protein production by human orbital fibroblasts. Ophthal Plast Reconstr Surg 1998;14:119-25.

11 Xing Z, Jordana $M$, Braciak T, et al. Lipopolysaccharide induces expression of granulocyte/macrophage colony-stimulating factor, interleukin-8, and interleukin-6 in human nasal, but not lung, fibroblasts: evidence for heterogeneity within the respiratory tract. Am J Respir Cell Mol Biol 1993:9:255-63.

12 Nakatsuka K, Tanaka Y, Hubscher S, et al. Rheumatoid synovial fibroblasts are stimulated by the cellular adhesion to T cells through lymphocyte function associated antigen- 1/intercellular adhesion molecule-1. J Rheumatol 1997:24:458-64

13 Stamenkovic I, Clark EA, Seed B. A B-lymphocyte activation molecule related to the nerve growth factor receptor and induced by cytokines in carcinomas. Embo J 1989;8:1403-10.

14 Durie FH, Foy TM, Masters SR, et al. The role of CD40 in the regulation of humoral and cell-mediated immunity. Immunol Today 1994;15:406-11.

15 Banchereau J, Bazan F, Blanchard D, et al. The CD40 antigen and its ligand. Annu Rev Immunol 1994; 12:881-922.

16 Stout RD, Suttles J. The many roles of CD40 in cell-mediated inflammatory responses. Immunol Today 1996;17:487-92.

17 Schonbeck U, Libby P. The CD40/CD154 receptor/ligand dyad. Cell Mol Life Sci 2001;58:4-43.

18 Cella M, Scheidegger D, Palmer-Lehmann K, et al. Ligation of CD40 on dendritic cells triggers production of high levels of interleukin-12 and enhances T cell stimulatory capacity: T-T help via APC activation. J Exp Med 1996; 184:747-52

19 Pinchuk LM, Klaus SJ, Magaletti DM, et al. Functional CD40 ligand expressed by human blood dendritic cells is up-regulated by CD40 ligation. J Immunol 1996; 157:4363-70

20 Bjorck P, Banchereau J, Flores-Romo L. CD40 ligation counteracts Fasinduced apoptosis of human dendritic cells. Int Immunol 1997:9:365-72.

21 Brouty-Boye D, Pottin-Clemenceau C, Doucet C, et al. Chemokines and CD40 expression in human fibroblasts. Eur J Immunol 2000;30:914-19.

22 Dongari-Bagtzoglou Al, Warren WD, Berton MT, et al. CD40 expression by gingival fibroblasts: correlation of phenotype with function. Int Immunol 1997;9:1233-41.

23 Cao HJ, Wang HS, Zhang Y, et al. Activation of human orbital fibroblasts through CD40 engagement results in a dramatic induction of hyaluronan synthesis and prostaglandin endoperoxide $\mathrm{H}$ synthase- 2 expression. Insights into potential pathogenic mechanisms of thyroid-associated ophthalmopathy. J Biol Chem 1998;273:29615-25.

24 Sempowski GD, Chess PR, Phipps RP. CD40 is a functional activation antigen and B7-independent $T$ cell costimulatory molecule on normal human lung fibroblasts. J Immunol 1997; 158:4670-7.

25 Sempowski GD, Rozenblit J, Smith TJ, et al. Human orbital fibroblasts are activated through $\mathrm{CD} 40$ to induce proinflammatory cytokine production. Am J Physiol 1998;274:C707-14.

26 van Kooten C, Banchereau J. Functional role of CD40 and its ligand. Int Arch Allergy Immunol 1997; 1 13:393-9.

27 Laman JD, De Boer M, Hart BA. CD40 in clinical inflammation: from multiple sclerosis to atherosclerosis. Dev Immunol 1998:6:215-22.

28 Grewal IS, Flavell RA. The role of CD40 ligand in costimulation and T-cell activation. Immunol Rev 1996;153:85-106.

29 Fanslow WC, Srinivasan S, Paxton R, et al. Structural characteristics of CD40 ligand that determine biological function. Semin Immunol 1994:6:267-78.

30 Wykes M, Poudrier J, Lindstedt R, et al. Regulation of cytoplasmic, surface and soluble forms of CD40 ligand in mouse B cells. Eur J Immunol 1998;28:548-59.

31 Bishop GA, Hostager BS. Molecular mechanisms of CD40 signaling. Arch Immunol Ther Exp 2001;49:129-37.

32 van Kooten C, Banchereau J. CD40-CD40 ligand. J Leukoc Biol 2000:67:2-17.

33 Werneburg BG, Zoog SJ, Dang T, et al. Molecular characterization of CD40 signaling intermediates. J Biol Chem $2001 ; 276: 43334-42$.

34 Hostager BS, Catlett IM, Bishop GA. Recruitment of CD40 and tumor necrosis factor receptor-associated factors 2 and 3 to membrane microdomains during CD40 signaling. J Biol Chem 2000;275:15392-8.

35 Hostager BS, Bishop GA. Cutting edge: contrasting roles of TNF receptorassociated factor 2 (TRAF2) and TRAF3 in CD40-activated B lymphocyte differentiation. J Immunol 1999;162:6307-11.

36 Pullen SS, Dang TT, Crute JJ, et al. CD40 signaling through tumor necrosis factor receptor-associated factors (TRAFs). Binding site specificity and activation of downstream pathways by distinct TRAFs. J Biol Chem 1999;274: 14246-54

37 Rothe M, Sarma V, Dixit VM, et al TRAF2-mediated activation of NF-kappa B by TNF receptor 2 and CD40. Science 1995;269:1424-7.

38 Nakano H, Sakon S, Koseki H, et al. Targeted disruption of Traf5 gene causes defects in CD40- and CD27-mediated lymphocyte activation. Proc Natl Acad Sci U S A 1999:96:9803-8.

39 Ahonen C, Manning E, Erickson LD, et al. The CD40-TRAF6 axis controls affinity maturation and the generation of long-lived plasma cells. Nat Immunol 2002;3:451-6.

40 Lomaga MA, Yeh WC, Sarosi I, et al. TRAF6 deficiency results in osteopetrosis and defective interleukin-1, CD40, and LPS signaling. Genes Dev 1999; 13:1015-24.

41 Stuber E, Strober W, Neurath M. Blocking the CD4OL-CD40 interaction in vivo specifically prevents the priming of $\mathrm{T}$ helper 1 cells through the inhibition of interleukin 12 secretion. J Exp Med 1996;183:693-8.

42 Liv Z, Geboes K, Colpaert S, et al. Prevention of experimental colitis in SCID mice reconstituted with CD45RBhigh CD4+T cells by blocking the CD40 CD154 interactions. J Immunol 2000; 164:6005-14.

43 De Jong YP, Comiskey M, Kalled SL, et al. Chronic murine colitis is dependent on the CD154/CD40 pathway and can be attenuated by anti-CD154 administration. Gastroenterology 2000;119:715-23

44 van Kooten C. Immune regulation by CD40-CD40-I interactions-2; Y2K update. Front Biosci 2000;5:D880-693.

45 Doucet C, Giron-Michel J, Canonica GW, et al. Human lung myofibroblasts as effectors of the inflammatory process: the common receptor gamma chain is induced by Th2 cytokines, and CD40 ligand is induced by lipopolysaccharide, thrombin and TNF-alpha. Eur J Immunol 2002;32:2437-49.

46 Lazaar AL, Amrani Y, Hsu J, et al. CD40-mediated signal transduction in human airway smooth muscle J Immunol 1998:161:3120-7.

47 Liu Z, Colpaert S, D'Haens GR, et al. Hyperexpression of CD40 ligand (CD154) in inflammatory bowel disease and its contribution to pathogenic cytokine production. J Immunol 1999; 163:4049-57.

48 Sawada-Hase N, Kiyohara T, Miyagawa J, et al. An increased number of CD40-high monocytes in patients with Crohn's disease. Am J Gastroenterol 2000;95:1516-23.

49 Vuckovic S, Florin TH, Khalil D, et al. CD40 and CD86 upregulation with divergent CMRF44 expression on blood dendritic cells in inflammatory bowe diseases. Am J Gastroenterol 2001:96:2946-56.

50 Polese L, Angriman I, Cecchetto A, et al. The role of CD40 in ulcerative colitis: histochemical analysis and clinical correlation. Eur J Gastroenterol Hepatol 2002; 14:237-41.

51 Ludwiczek O, Kaser A, Tilg H. Plasma levels of soluble CD40 ligand are elevated in inflammatory bowel diseases. Int $J$ Colorectal Dis 2003; 18:142-7.

52 Rogler G, Hausmann M, Vogl D, et al. Isolation and phenotypic characterization of colonic macrophages. Clin Exp Immunol 1998; 112:205-15.

53 Rogler G, Brand K, Vogl D, et al. Nuclear factor kappaB is activated in macrophages and epithelial cells of inflamed intestinal mucosa. Gastroenterology 1998:115:357-69.

54 Musso A, Condon TP, West GA, et al. Regulation of ICAM-1-mediated fibroblast-T cell reciprocal interaction: implications for modulation of gut inflammation. Gastroenterology 1999; 117:546-56. 